
\title{
Ultraviolet light and laser irradiation enhances the antibacterial activity of glucosamine-functionalized gold nanoparticles
}

This article was published in the following Dove Press journal:

International Journal of Nanomedicine

25 August 2015

Number of times this article has been viewed

\author{
Saravanan Govindaraju',3 \\ Mohankandhasamy \\ Ramasamy' \\ Rengarajan Baskaran ${ }^{2}$ \\ Sang Jung Ahn ${ }^{3,4}$ \\ Kyusik Yun' \\ 'Department of Bionanotechnology, \\ Gachon University, Gyeonggi-do, \\ ${ }^{2}$ College of Pharmacy, Gachon \\ University, Incheon, ${ }^{3}$ Centre for \\ Advanced Instrumentation, Korea \\ Research Institute of Standard and \\ Science, University of Science and \\ Technology, Daejeon, Republic \\ of Korea; ${ }^{4}$ Major of Nano Science, \\ University of Science and Technology, \\ Daejeon, Republic of Korea
}

\begin{abstract}
Here we report a novel method for the synthesis of glucosamine-functionalized gold nanoparticles (GlcN-AuNPs) using biocompatible and biodegradable glucosamine for antibacterial activity. GlcN-AuNPs were prepared using different concentrations of glucosamine. The synthesized AuNPs were characterized for surface plasmon resonance, surface morphology, fluorescence spectroscopy, and antibacterial activity. The minimum inhibitory concentrations (MICs) of the AuNPs, GlcN-AuNPs, and GlcN-AuNPs when irradiated by ultraviolet light and laser were investigated and compared with the MIC of standard kanamycin using Escherichia coli by the microdilution method. Laser-irradiated GlcN-AuNPs exhibited significant bactericidal activity against $E$. coli. Flow cytometry and fluorescence microscopic analysis supported the cell death mechanism in the presence of GlcN-AuNP-treated bacteria. Further, morphological changes in $E$. coli after laser treatment were investigated using atomic force microscopy and transmission electron microscopy. The overall results of this study suggest that the prepared nanoparticles have potential as a potent antibacterial agent for the treatment of a wide range of disease-causing bacteria.
\end{abstract}

Keywords: gold nanoparticles, glucosamine, light irradiation, antibacterial activity, bacterial morphology

\section{Introduction}

Nanotechnology has been a rapidly growing field in recent decades, with numerous applications in science and technology. Despite concerns about the potential ecological and environmental hazards posed by this technology, nanoparticles hold promise as antibacterial agents because of their photoactive bactericidal effects. ${ }^{1}$ Recently, there have been a number of nanoparticle-based studies showing the diverse effects of nanoparticles developed to prevent or destroy microbial growth, which could be linked to the nature of nanomaterials, the size of nanoparticles, and/or other external factors. ${ }^{2,3}$ The antibacterial activity of metal nanoparticles has an important role in the manufacture of medical devices, food processing, and water treatment. ${ }^{4,5}$

Metals have been used for centuries as bactericidal and bacteriostatic agents, and materials such as silver, gold, and zinc nanoparticles are the subject of intensive research in science and technology. ${ }^{6}$ Metal nanoparticles with a high specific surface area and a high proportion of surface atoms have been studied widely due to their unique physicochemical characteristics, which include size, optical activity, catalytic activity, and antimicrobial activity. ${ }^{7,8}$ Gold nanoparticles (AuNPs) has been described as being of great interest for biomedical applications, including drug delivery, imaging, and diagnostics. In particular, AuNPs have been extensively 
investigated for their potential bactericidal activity, which involves inactivation of bacteria by interaction with functional groups on the bacterial cell wall. The antimicrobial activity of AuNPs may be attributed to their toxic effects on bacterial cells. ${ }^{9}$

Functionalization of selective biomolecules developed using nanoparticles for environmentally benign antibacterial applications requires a suitable surface or interface linking agent to immobilize the functional moiety. ${ }^{10,11}$ Stabilized surface engineering of metal nanoparticles also enhances antibacterial activity which minimizing unwanted toxicity. To date, a variety of methods for synthesis of AuNPs have been studied, reported, and reviewed, including thermolysis and microwave irradiation, along with conventional methods involving reduction of gold salts by reducing agents such as sodium borohydride, sodium citrate, glucose, chitosan, gelatin, and lysozyme. ${ }^{12}$ Glucosamine is an amine monosaccharide which is known to be safe and has been demonstrated to have potential biological applications for the treatment of various inflammatory diseases, including osteoarthritis and rheumatoid arthritis. ${ }^{13}$

Despite the broad range of AuNPs synthesized and biologically evaluated in the literature, there have been few systematic studies of the interaction between functionalized nanoparticles and cells. Therefore, we developed glucosamine-functionalized (GlcN)-AuNPs using different concentrations of the functional group based on a gold core. Here we report our preliminary results for functionalized GlcN-AuNPs manufactured using a clean process of sizecontrollable AuNPs in the presence of chitosan. Particle size, ultraviolet-visible absorbance, functional groups, and morphology were characterized. These nanoparticles showed promising antibacterial activity after ultraviolet germicidal irradiation and laser exposure. The antibacterial activity was calculated by minimum inhibitory concentration (MIC) method.

\section{Materials and methods Materials}

Gold (III) chloride $\left(\mathrm{HAuCl}_{4}\right)$, chitosan, and $\mathrm{GlcN}$ (in the form of D-glucosamine hydrochloric acid) were obtained commercially from Sigma-Aldrich (USA). Glutaraldehyde was purchased from Junsei (Japan). Luria-Bertani broth was obtained from Amresco (USA) and Mueller-Hinton agar was sourced from Difco (USA). A Live/Dead ${ }^{\circledR}$ BacLight $^{\mathrm{TM}}$ bacterial viability kit was purchased from Invitrogen (USA). Milli-Q water with a resistance greater than $18 \mathrm{M} \Omega$ was used in the experiments.

\section{Instrumentation}

Specific optical observations of ultraviolet-visible spectra were taken for the AuNPs and the different concentrations of GlcN-AuNPs using a Varian Cary 50 ultraviolet spectrophotometer. Functional groups and stretching and bending vibrations in the chemical entities were studied using a Micro-Raman system (Ramboss 500i) He-NE laser beam at $633 \mathrm{~nm}$ and 1,800 lines per mm grating with 50X objective lens at room temperature. The average particle size distributions for the AuNPs and the GlcN-AuNPs were measured by dynamic light scattering using a Malvern Zetasizer Nano ZS.

Morphological characteristics were studied using an FEI Titan 80-300 high-resolution transmission electron microscope, a JEOL JSM-7500F field emission scanning electron microscope, and a JPK NanoWizard II bioatomic force microscope. For the TEM images, $10 \mu \mathrm{L}$ samples were placed on a copper grid and dried overnight at room temperature. Images were acquired at an accelerating voltage up to $300 \mathrm{kV}$. The morphological structure of the nanoparticles was analyzed using the bioatomic force microscope, with the sample placed on a slide and measured according to the protocol at $20 \mathrm{kV}$ in contact mode. For morphological characterization by field emission scanning electron microscopy, a sample was placed onto the surface of a silica-coated substrate $\left(1 \times 1 \mathrm{~cm}^{2}\right)$, dried at room temperature, and imaged. For the Live/Dead bacteria assay, the stained samples were analyzed using a Nikon Eclipse TE 2000-U laser scanning fluorescence microscope.

\section{Synthesis of AuNPs}

The AuNPs were synthesized using a previously reported method with slight modification. ${ }^{14}$ Briefly, chitosan $(0.53 \% \mathrm{w} / \mathrm{v})$ was dissolved in $1 \%$ acetic acid solution after which an equal volume of $\mathrm{HAuCl}_{4}(0.32 \% \mathrm{w} / \mathrm{v})$ was added with continuous stirring at $800 \mathrm{rpm}$ and at $90^{\circ} \mathrm{C}$ until the color changed from yellow to wine red. The sample was brought to room temperature and sonicated for 5 minutes using a Sonics VC 505 probe sonicator at $30 \%$ amplitude and with a 1 -second pulse on-off cycle. The prepared AuNPs were then stored at room temperature until further use.

\section{Synthesis of GlcN-AuNPs}

The GlcN-AuNPs were synthesized using different concentrations of glucosamine. Appropriate amounts of glucosamine were injected into round-bottomed flasks containing equal volumes of AuNPs at a specific flow rate $(0.16 \mathrm{~mL} / \mathrm{min})$ controlled by a syringe pump. The mixture was stirred at 
$800 \mathrm{rpm}$ using a magnetic stirrer. This procedure was used to synthesize the different concentrations of GlcN-AuNPs. Glucosamine was used at final concentrations of 0.021 (F1) 0.043 (F2), 0.086 (F3), and $0.12 \% \mathrm{w} / \mathrm{v}$ (F4). The concentration of AuNPs was kept constant in all the formulations. The prepared nanoparticles were filtered and stored until further analysis.

\section{Antibacterial studies}

A Gram-negative strain of bacteria (E. coli) was purchased from the Korean Agricultural Culture Collection (10005) in South Korea and used for the antibacterial activity studies. The antibacterial activity was determined by the microdilution method using a 96-well plate. ${ }^{15}$ The inoculate was prepared by suspending $10^{5}$ colony-forming units $/ \mathrm{mL}$ of cells in sterile Luria-Bertani medium. After reaching confluence, cells were treated with appropriate amounts of the synthesized nanoparticles. The final volume $(0.2 \mathrm{~mL})$ was fixed for each well. After incubation at $35^{\circ} \mathrm{C}$ for 24 hours, the micro-well plates were measured at $600 \mathrm{~nm}$ using a PerkinElmer Victor X5 multimode plate reader to determine the MIC value.

To investigate the effect of irradiation on the nanoparticles, the prepared GlcN-AuNPs were exposed to ultraviolet light $(254 \mathrm{~nm})$ and a DPSS laser $(671 \mathrm{~nm})$ for 20 minutes before they were used to treat the bacteria. The MIC was defined as the lowest concentration of the nanoparticle formulation at which maximum bacterial growth inhibition occurred. Kanamycin was used as the standard reference antibiotic. All experiments were performed in triplicate and mean average values are reported.

\section{Morphological characterization of nanoparticle-treated bacteria}

Morphological changes in $E$. coli after treatment with the nanoparticles was observed using atomic force microscopy (AFM) and TEM. The E. coli bacteria were treated with the nanoparticles, incubated for 24 hours, washed with distilled water, and then fixed on microscope cover slips for imaging by AFM. For the TEM analysis, E. coli bacteria were fixed on the carbon grid with $1 \%$ glutaraldehyde, dried at room temperature, and imaged.

\section{Analysis of bacteria by flow cytometry}

Fluorescence-activated cell sorting analysis was performed using the commercially available Live/Dead BacLight bacterial viability kit (Invitrogen) which identifies live and dead bacteria cells. The cultured $E$. coli cells were treated with nanoparticles based on the MIC results $(100 \mu \mathrm{g} / \mathrm{mL})$ and incubated for 24 hours. After incubation, the bacterial cells were stained with a 1:1 mixture of SYTO9 and propidium iodide. The samples were incubated at room temperature for 15 minutes in the dark. Flow cytometric measurements were performed at an excitation wavelength of $488 \mathrm{~nm}$ using an optical filter set-up whereby red fluorescence was measured above $630 \mathrm{~nm}$ (FL3) and green fluorescence was measured at $520 \mathrm{~nm}$ (FL1). The trigger was set for the green fluorescence channel (FL1).

\section{Fluorescence microscopy analysis}

The viability of the nanoparticle-treated bacterial cells was assessed using the Live/Dead BacLight bacterial viability kit staining technique containing SYTO9 and propidium iodide. The SYTO9 enters the membrane of the bacteria cell, giving a green color for live bacteria, and propidium iodide enters the damaged cell membrane, giving a red color for dead bacteria.

\section{Results and discussion}

In this study, we synthesized AuNPs using chitosan as a reducing agent. AuNPs were prepared by adding an acidic aqueous solution of chitosan to a chloroauric acid $\left(\mathrm{HAuCl}_{4}\right)$ at $80^{\circ} \mathrm{C}$, resulting in a color change from light yellow to wine red. Formation of the AuNPs was confirmed by ultravioletvisible spectroscopy, and was hypothesized to be due to the degree of electrostatic or chemical interaction between $\mathrm{AuCl}_{4}^{-}$ions and the $\mathrm{NH}_{3}^{+}$in the protonated chitosan at low $\mathrm{pH}$. This promotes the reduction of the gold precursor in the presence of chitosan on the surface.

We used glucosamine as a surface-functionalized material in view of its chemical characteristics, biocompatibility, and absorption enhancement properties. Due to its electrostatic nature, glucosamine prevents aggregation of AuNPs. It was envisaged that the charge on the amino groups would enable optimum stability and improve the intracellular uptake of the AuNPs. Further, we used different concentrations of glucosamine to determine the effect of surface functionalization without changes in the concentration of AuNPs, and demonstrated that lower concentrations of glucosamine resulted in aggregated particles. However, the glucosamine itself showed no aggregation.

Figure 1 gives the ultraviolet-visible spectra for the AuNPs and GlcN-AuNPs, and shows a characteristic surface plasmon resonance (SPR) absorption band approximately 520-560 nm, indicating formation of AuNPs. ${ }^{16-18}$ The AuNPs prepared with chitosan showed an absorption band at $520 \mathrm{~nm}$, and 


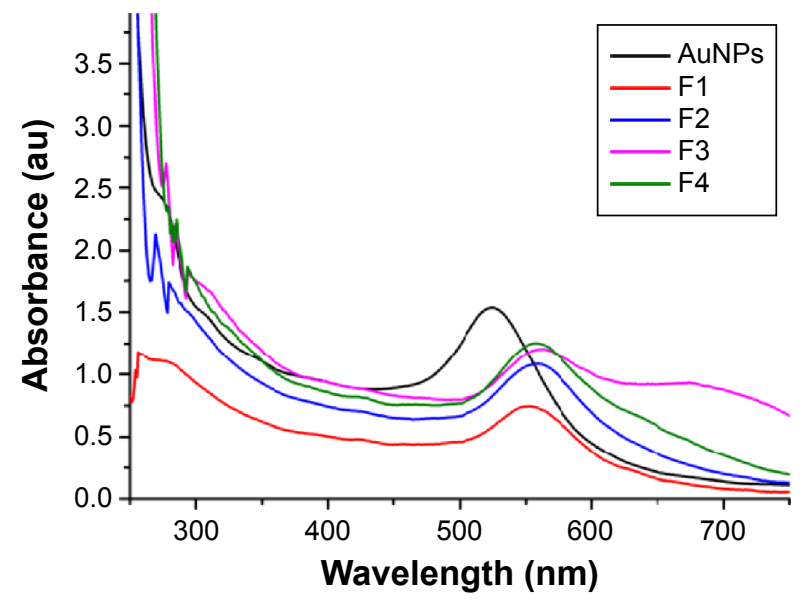

Figure I Visible absorption spectra for AuNPs without glucosamine and AuNPs functionalized with different concentrations of glucosamine, ie, (FI) $0.021 \% \mathrm{w} / \mathrm{v}$, (F2) $0.043 \% \mathrm{w} / \mathrm{v},(\mathrm{F} 3) 0.086 \% \mathrm{w} / \mathrm{v}$, and (F4) $0.12 \% \mathrm{w} / \mathrm{v}$.

Abbreviations: au, absorbance unit; AuNPs, gold nanoparticles; F, formulation.

surface functionalization of the AuNPs with glucosamine resulted in a significant shift in the SPR band to approximately $540-560 \mathrm{~nm}$, reflecting a red and blue shift of the spectrum depending on the surface, size, and shape of the nanoparticles. The surface of AuNPs contain collective oscillation of electrons, which are correlated in the electromagnetic field of observing light ${ }^{19}$ and this phenomena elucidates the causes of aggregation due to lower concentration of GlcN.

Raman spectroscopy is used to observe vibration, modes system, and analyze the bonding characteristics of carbon materials. The laser lights interact with the molecular vibrations in the form of an inelastic light scattering where a photon excites the molecules can be ground or excited state than the incoming photon. The AuNPs excited by laser beam with molecular vibration, resulted in an increase in the electrostatic fields surrounding the metals. ${ }^{20}$ Using this technique, a typical Raman band over the range of $300-900 \mathrm{~cm}^{-1}$ was observed for the AuNPs and GlcN-AuNPs (Figure 2). The shift obtained for the AuNPs and GlcN-AuNPs at $493 \mathrm{~cm}^{-1}$ indicates the $v$ (metal-o) band, which generally indicates the presence of a metal. ${ }^{21}$ Further, the Raman shifts found at 419 and $709 \mathrm{~cm}^{-1}$ indicate $\delta(\mathrm{CC})$ and C-C skeletal vibrations, confirming the presence of GlcN-AuNPs. The band observed at approximately $570-630 \mathrm{~cm}^{-1}$ indicates the $\mathrm{N}-\mathrm{C}=\mathrm{O}$ group found in amides. ${ }^{22}$

The average particle size of the synthesized AuNPs and GlcN-AuNPs was measured using a Malvern particle size analyzer. Figure 3 shows that the mean particle size for the AuNPs was $100.51 \pm 4.39 \mathrm{~nm}$ and the polydispersity index (PDI) was 0.504. After addition of glucosamine, the mean particle size decreased to $93.36 \pm 0.58 \mathrm{~nm}$. When the

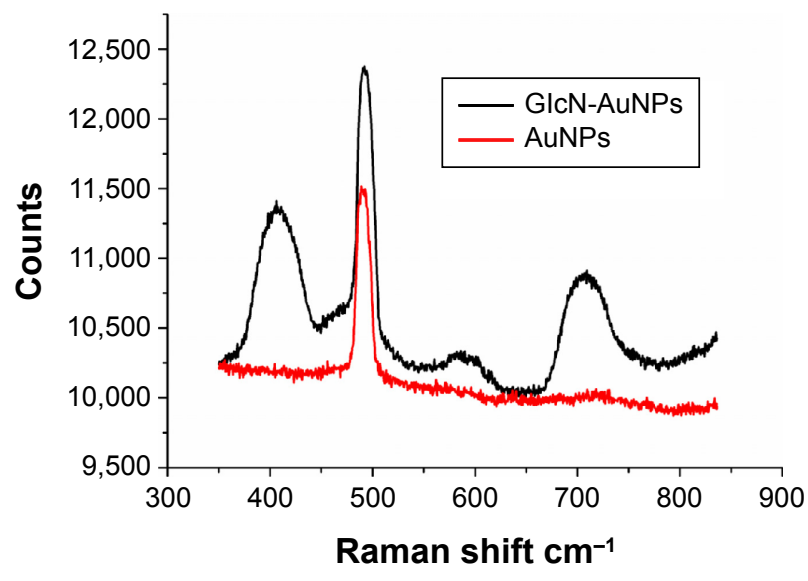

Figure 2 Raman spectra for AuNPs and GlcN-AuNPs.

Abbreviations: AuNPs, gold nanoparticles; GlcN-AuNPs, glucosamine-functionalized gold nanoparticles.

glucosamine concentration was increased, the particle size decreased in a concentration-dependent manner. The smallest nanoparticle size $(78.39 \pm 0.61 \mathrm{~nm})$ was observed at the highest concentration of glucosamine used in our study. A significant change in particle size was observed at higher concentrations of glucosamine when compared with the AuNPs.

The morphology of the AuNPs and GlcN-AuNPs was characterized by field emission scanning electron microscopy, AFM, and transmission electron microscopy, and all the formulations were found to have a spherical shape. ${ }^{23}$ The charge rendered is insufficient in AuNPs, leading to sensitization of the particles causing aggregation. The scanning electron micrographs provided in Figure 4 that show some aggregated AuNPs. However, higher concentrations of glucosamine conferred sufficient charge, rendering the nanoparticles electrostatically stable and preventing interaction between them. Figure 5 shows the two-dimensional and

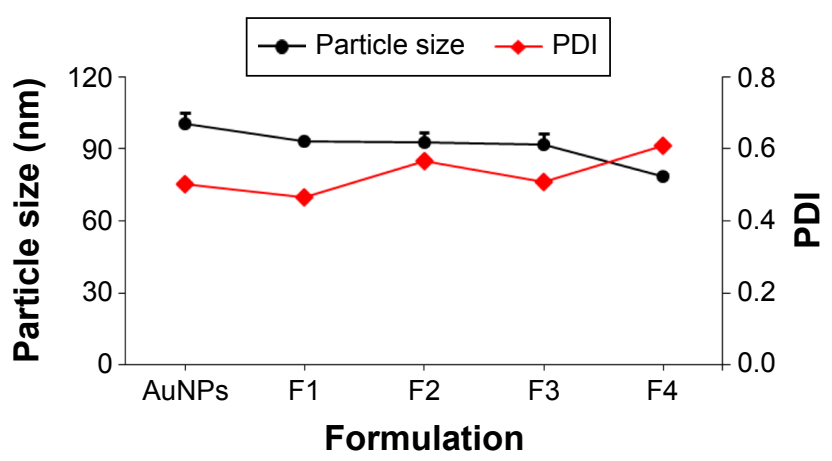

Figure 3 Particle size distribution for AuNPs without glucosamine and AuNPs functionalized with different concentrations of glucosamine, ie, (FI) $0.021 \% \mathrm{w} / \mathrm{v}$, (F2) $0.043 \% \mathrm{w} / \mathrm{v},(\mathrm{F} 3) 0.086 \% \mathrm{w} / \mathrm{v}$, and $(\mathrm{F} 4) 0.12 \% \mathrm{w} / \mathrm{v}(\mathrm{n}=3)$.

Abbreviations: AuNPs, gold nanoparticles; GlcN-AuNPs, glucosamine-functionalized gold nanoparticles; PDI, polydispersity index; F, formulation. 

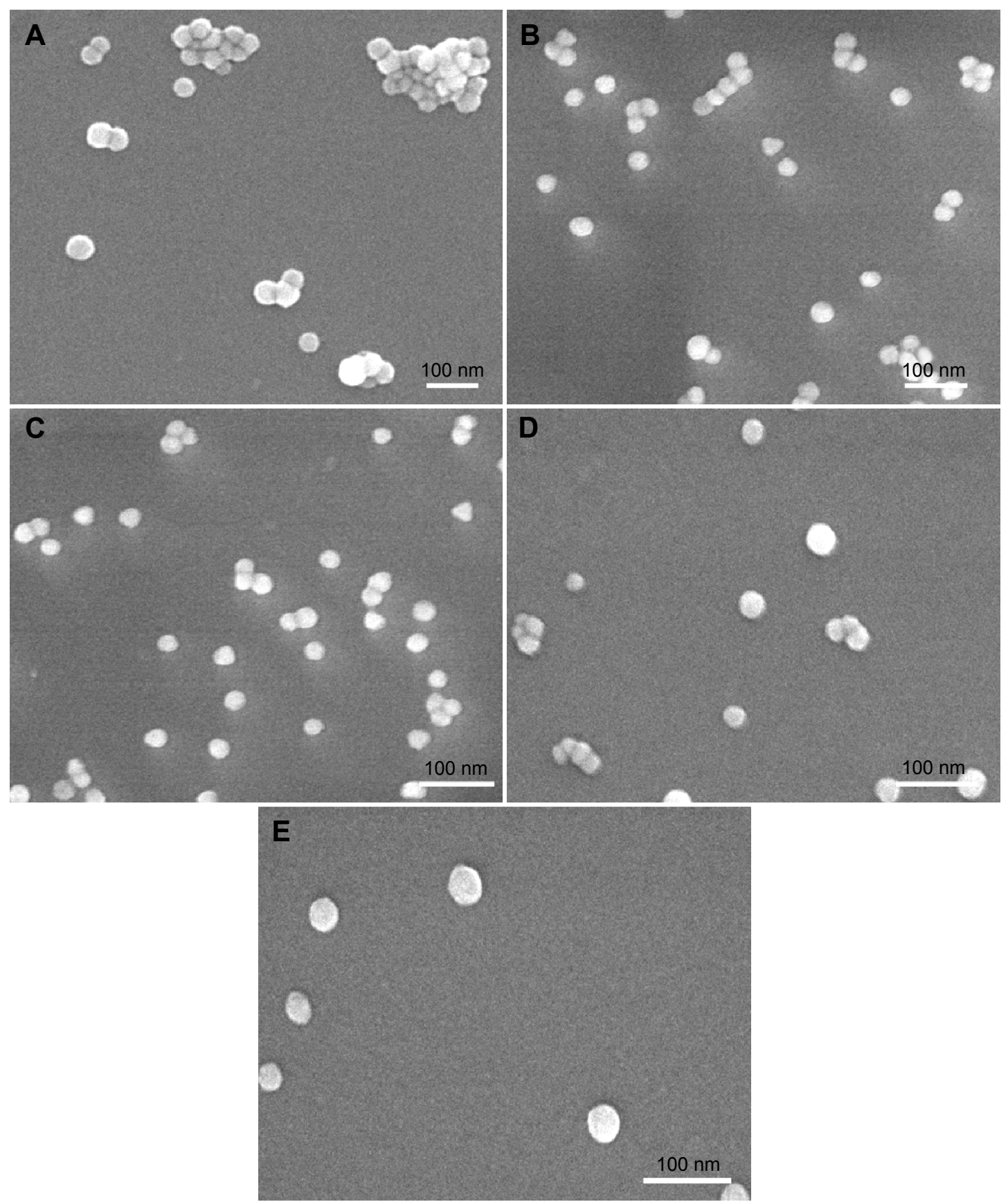

Figure 4 SEM images of AuNPs.

Notes: Scanning electron micrographs of AuNPs without glucosamine (A) and AuNPs functionalized with different concentrations of glucosamine, ie, (B) (FI) 0.02 I\% w/v, (C) (F2) $0.043 \% \mathrm{w} / \mathrm{v}$, (D) (F3) $0.086 \% \mathrm{w} / \mathrm{v}$, and (E) (F4) $0.12 \% \mathrm{w} / \mathrm{v}$ of GlcN concentration.

Abbreviations: AuNPs, gold nanoparticles; F, formulation; GlcN, glucosamine.

three-dimensional AFM images of AuNPs and GlcN-AuNPs. The two-dimensional images show individual spherical particles in both formulations and the three-dimensional images show the height of the nanoparticle formulations, which was maximal for the AuNPs, reflecting the hefty particles present in AuNPs, which the GlcN-AuNPs were present discrete particles. Figure 6 shows the same results on AFM, further confirming the TEM findings. In particular, a coating of glucosamine can be seen on the outside of the nanoparticles. Figure 6D shows that nanoparticles approximately $1.8 \mathrm{~nm}$ in height are coated with glucosamine.

Growth of E. coli in the presence of the AuNPs is shown in Figure 7. We investigated the inhibitory effect of the nanoparticles over a period of 24 hours, which allows for the different phases of bacterial growth to take place. Cells not treated with AuNPs or treated with a standard drug were used as controls. 

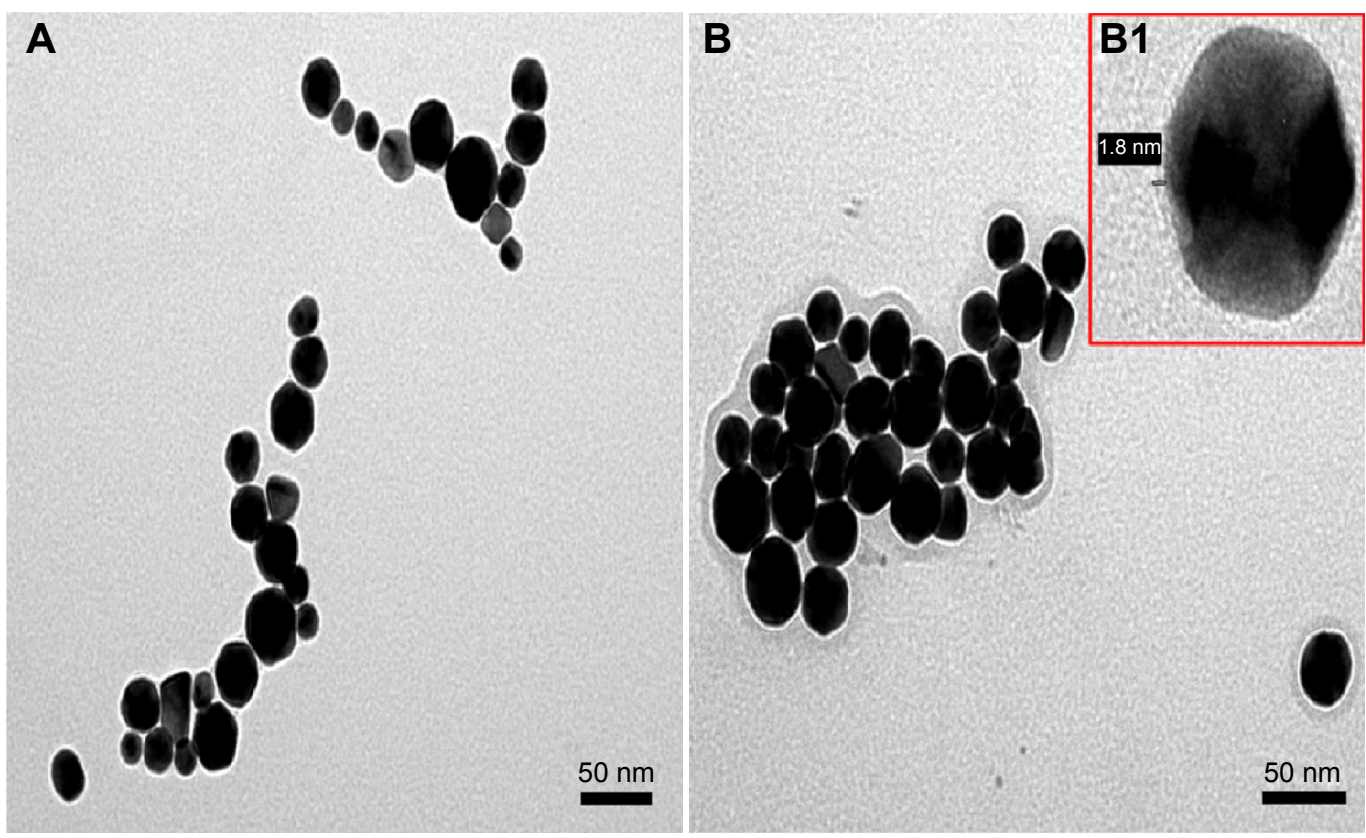

Figure 5 TEM images of AuNPs and GlcN-AuNPs.

Notes: Transmission electron micrographs of $(\mathbf{A})$ AuNPs and $(\mathbf{B})$ glucosamine-functionalized AuNPs showing their particle size distribution and shape. The inset image (BI) indicates the width of a single glucosamine-functionalized nanoparticle.

Abbreviations: AuNPs, gold nanoparticles; GlcN-AuNPs, glucosamine-functionalized gold nanoparticles.

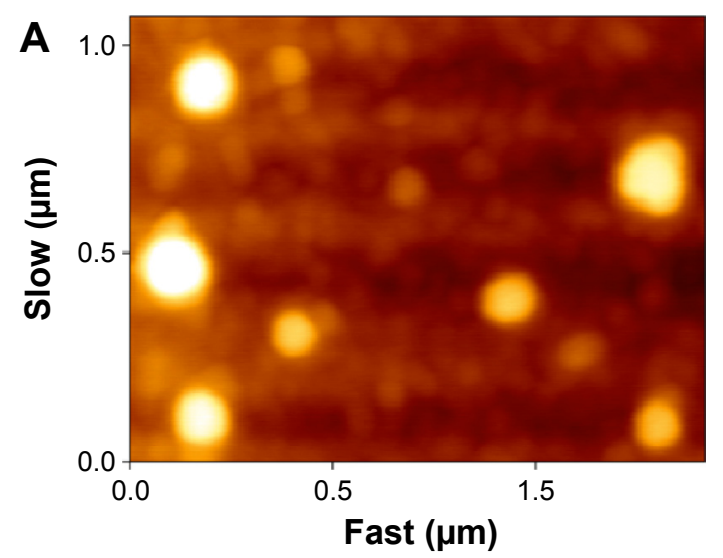

B
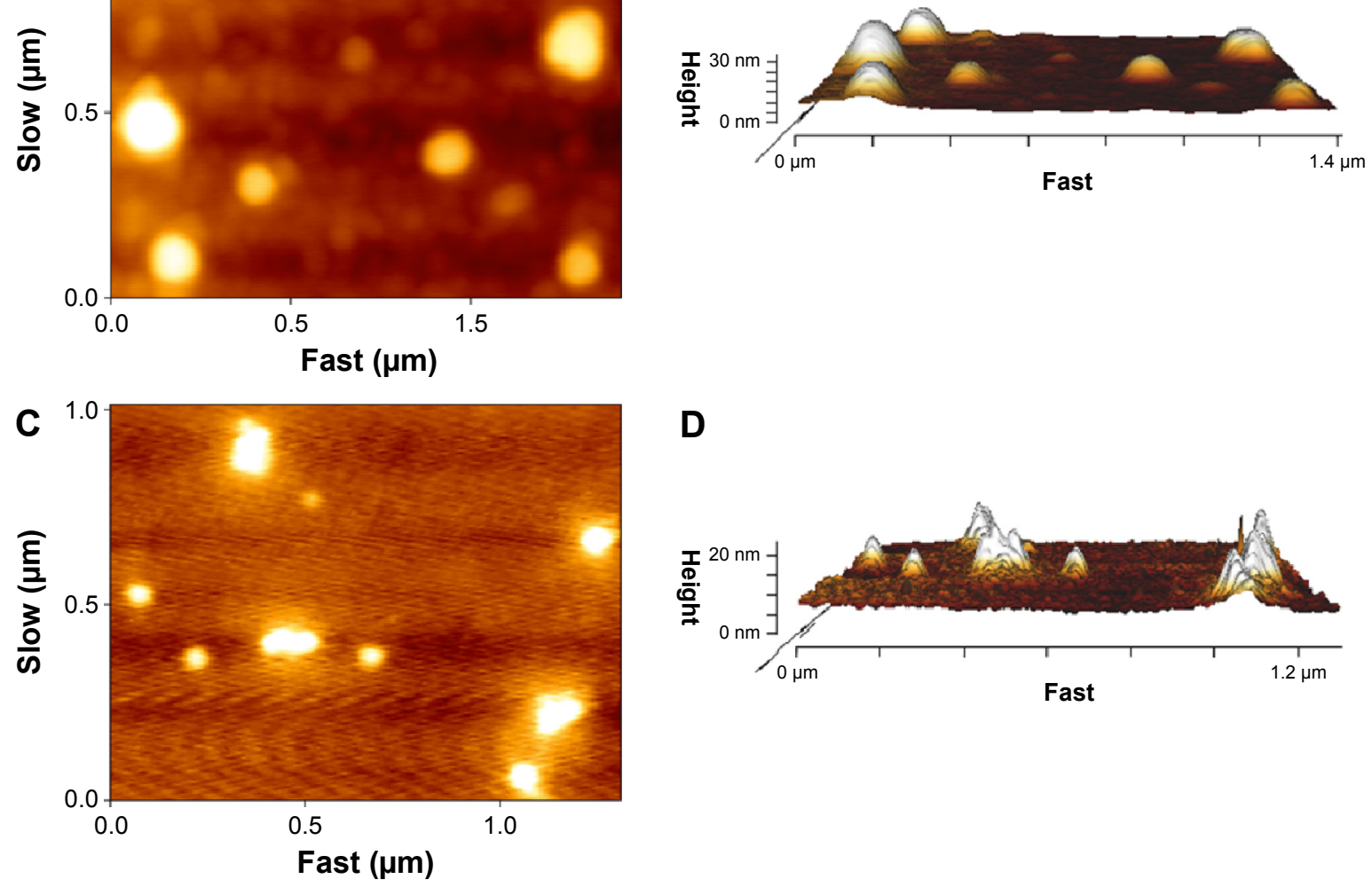

D

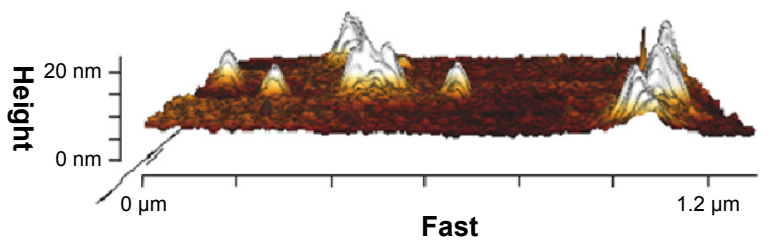

Figure 6 Atomic force micrographs of AuNPs (A, B) and GlcN-AuNPs (C, D).

Notes: $(\mathbf{A})$ and $(\mathbf{C})$ show the particle height and $(\mathbf{B})$ and $(\mathbf{D})$ represent three-dimensional images of the nanoparticles. Both of the formulations showed nanoparticles with a spherical shape.

Abbreviations: AuNPs, gold nanoparticles; GlcN-AuNPs, glucosamine-functionalized gold nanoparticles. 

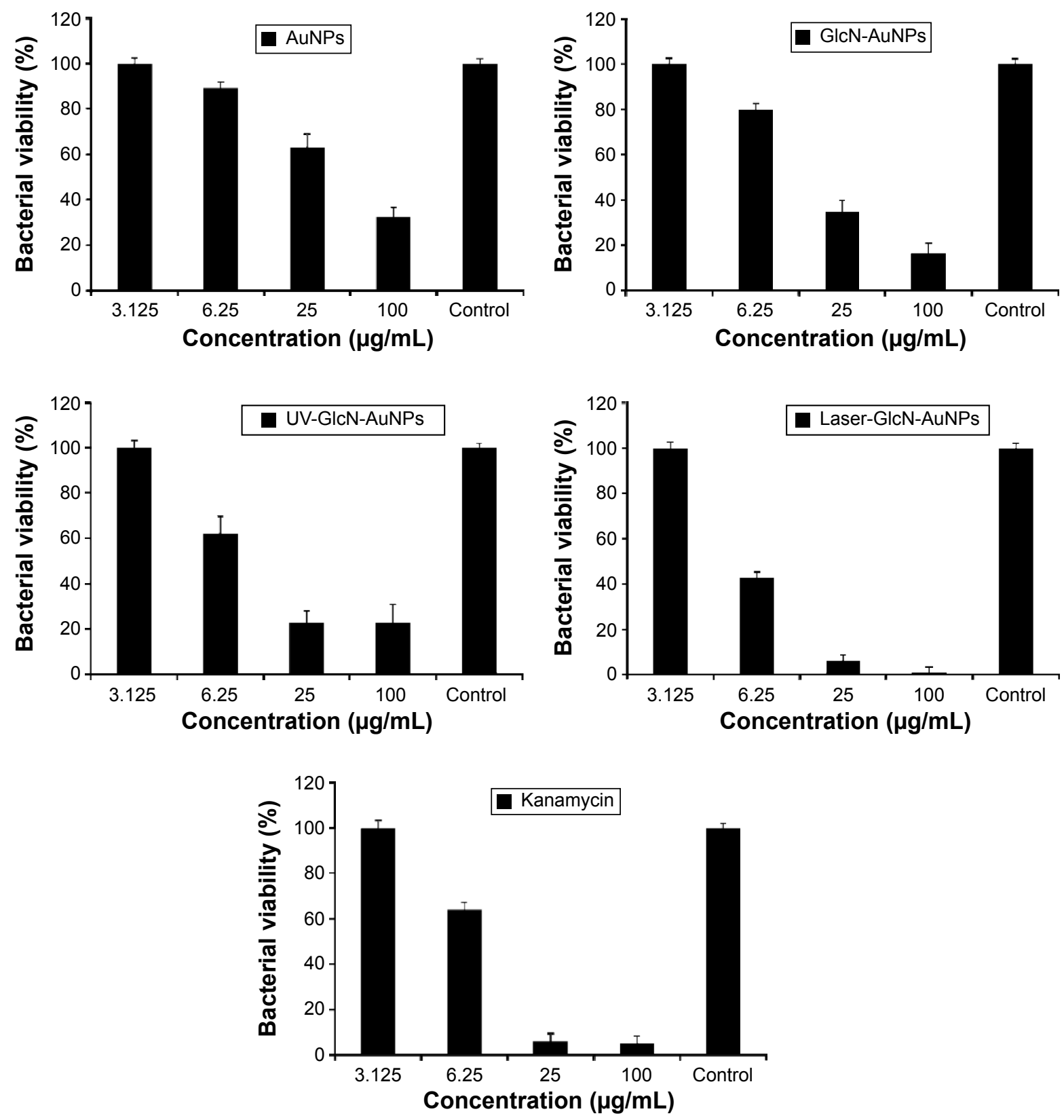

Figure 7 Antibacterial activity of AuNPs, GlcN-AuNPs, ultraviolet light-treated GlcN-AuNPs, laser-treated GlcN-AuNPs, and standard kanamycin.

Notes: A significant difference in activity was observed in all nanoparticle treatment groups when compared with the control $(P<0.00 \mathrm{I})$. The laser-treated GlcN-AuNPs showed better inhibition of bacterial growth at a low concentration when compared with other nanoparticles. A significant difference was observed between laser-treated GlcN-AuNPs and the other nanoparticles at high concentration $(P<0.00 \mathrm{I})$.

Abbreviations: AuNPs, gold nanoparticles; GlcN-AuNPs, glucosamine-functionalized gold nanoparticles.

After 24 hours of treatment with AuNPs $(25 \mu \mathrm{g} / \mathrm{mL})$, bacterial growth was observed to be $63.25 \% \pm 5.45 \%$, with no growth inhibition observed in the controls (only bacteria and medium). At the same concentration of GlcN-AuNPs, ultraviolet and laser exposure GlcN-AuNPs bacterial growth was observed $34.33 \% \pm 6.38 \%, 22.68 \% \pm 5.47 \%$, and $6.18 \% \pm 3.11 \%$, respectively. A significant difference in bacterial inhibition was observed when compared with the control $(P<0.001)$. Maximum inhibition of bacterial growth was observed for bacteria treated with GlcN-AuNPs exposed to laser when compared with the control $(P<0.0001)$. A significant difference was observed at the higher concentration when compared with non-exposed and ultraviolet light-treated GlcN-AuNPs $(P<0.001)$. This could be attributable to electrostatic attraction between the negatively charged bacterial cell membrane and the positively charged AuNPs. The morphology of the bacterial cell wall upon incubation with GlcN-AuNPs was analyzed further, and the findings support a bactericidal effect. 
Thus, treatment of microorganisms with GlcN-AuNPs resulted in greater inhibition of bacterial growth than that seen in the AuNP-treated group and controls. The smaller size of the GlcN-AuNPs could enable more nanoparticles to enter the microorganism, thereby increasing their antibacterial activity. Further, bacteria are distinct from eukaryotic cells in that they do not synthesize Glcn-6- $-\mathrm{PO}_{4}$; instead, Glcn-6- $\mathrm{PO}_{4}$ is converted directly into Glcn-1- $\mathrm{PO}_{4}$. Therefore, intracellular Glcn-6- $\mathrm{PO}_{4}$ would be expected to be present in bacteria only if they imported exogenous glucosamine. GlcN-AuNPs could be enter the bacterial cell via this mechanism. It emphasized that this is may be due to a higher amount of GlcN-AuNPs uptaken into bacteria and the increase in the antibacterial effect compared with the AuNPs. There has been a report suggesting that glucosamine produces oxidative stress with overproduction of reactive oxygen species (ROS) at the cellular level, thus leading to cell death. ${ }^{24}$ However, it must be noted that the mechanism of interaction between the cell membrane and glucosamine nanoparticles needs to be investigated further.

Gold-based materials exposed to ultraviolet light have a stronger antibacterial effect compared to its unexposed state, whereas standard antibiotic expressed in diminutive effect. These results ensure that a significant activation energy is created in gold based materials upon exposure to UV and laser irradiation which in turn was found to be the predominant reason of such notable antibacterial effect by GlcN-AuNPs. Irradiation with ultraviolet light probably triggers generation of ROS or radicals on the surface of glucosamine. ${ }^{24}$ Oxidative stress induced by generation of ROS might be a mechanism for the antibacterial activity of in AuNP systems. ${ }^{25}$ Thus, GlcNAuNPs may also have antibacterial activity when exposed to the photogeneration of the ROS induced by the surface of the GlcN-AuNPs. ${ }^{26}$ When E. coli bacteria were treated with AuNPs, changes in cell membrane morphology occurred, resulting into cell death. The exact mechanism via which this cell death occurs is still not completely understood. Here we exposed the irradiation with GlcN-AuNPs, before the treatment to bacteria, the surface of the metal absorb the irradiation and enhance the higher antibacterial effect. Phototherapy is widely used, and combines pulsed laser and nanoparticles such as AuNPs that are able to absorb light radiation and convert this into heat energy, which in turn has an antibacterial effect. ${ }^{27-29}$ In our study, the maximum antibacterial effect was found for nanoparticles exposed to irradiation. If we modify the surface of metal nanoparticles, we can control and target the desired antibacterial effect or other target drug delivery. By adjusting the treatment, duration of exposure, photostability, and surface-binding ligands, this nanoparticle system could be turned into a promising treatment for infectious diseases. For instance, laser-exposed GlcN-AuNPs had a strong antibacterial effect on $E$. coli, and it might be that the light energy is converted into more heat energy, which causes the damage to the biological membrane.

Herein, we found out the activation time of the drug into the microbe and demonstrated the morphological changes of E. coli after the intake of preparing GlcN-AuNPs, by using AFM and TEM. In this study, we used only GlcN-AuNPs, based on the MIC result that irradiation-exposed nanoparticles have a potent anti bacterial effect. The nanoparticle-treated bacteria were damaged and their morphology was changed, whereas the untreated bacteria had a well defined structure, were smooth, and generally showed typically rod-shaped cells. The TEM images in Figure 8 show that some of the small AuNPs (those less than $100 \mathrm{~nm}$ in size) had entered the bacterial cells. The AFM images in Figure 9 show the time dependence of the morphological changes in the bacteria, with increasing bacterial damage seen with increasing duration of treatment. The AFM images show no change to the outer surface of the membrane at 0 hour and subsequent morphological changes depending on duration of incubation. After 24 hours of incubation, the bacterial morphology was unstructured, indicated that GlcNAuNPs successfully entered the bacterial cells. With time, the approximate bacterial height decreased from $300 \mathrm{~nm}$ to $140 \mathrm{~nm}$, confirming these morphological changes.

Flow cytometry is performed using a combination of fluorescent markers, and is emerging as a leading technology for studying the viability of bacterial cells. The unique fluorescence pattern revealed by dual staining competes for the same target areas and interacts when present in the same location. Figure 10A shows that the bacterial cell population is almost $100 \%$ in the $\mathrm{R} 3$ region, with no bacterial cell death detected in the control. When the bacterial cells were treated with AuNPs, there was a shift to the $\mathrm{R} 2$ region, indicating that bacteria were being destroyed; however, there was no cell population in the $\mathrm{R} 1$ region, indicating that there were no dead bacteria. However, bacteria treated with AuNPs were found to be equally distributed in all regions, and GlcN-AuNPs exposed to ultraviolet and laser had more bacteria population in the R1 region compared to control. Laser-exposed GlcN-AuNPs treated bacteria maximum shifted to R1 region, indicating that maximum cell cycle arrest. Standard kanamycin was also showed more population in $\mathrm{R} 1$ region, where the similar results was acquired in MIC result.

Uptake by bacterial cells was studied using fluorescence microscopy with a commercially available LIVE/DEAD BacLight staining kit. Qualitative analysis of the nanoparticletreated bacteria was done using live/dead dual staining. Green fluorescing SYTO9 is able to enter all live cells, 

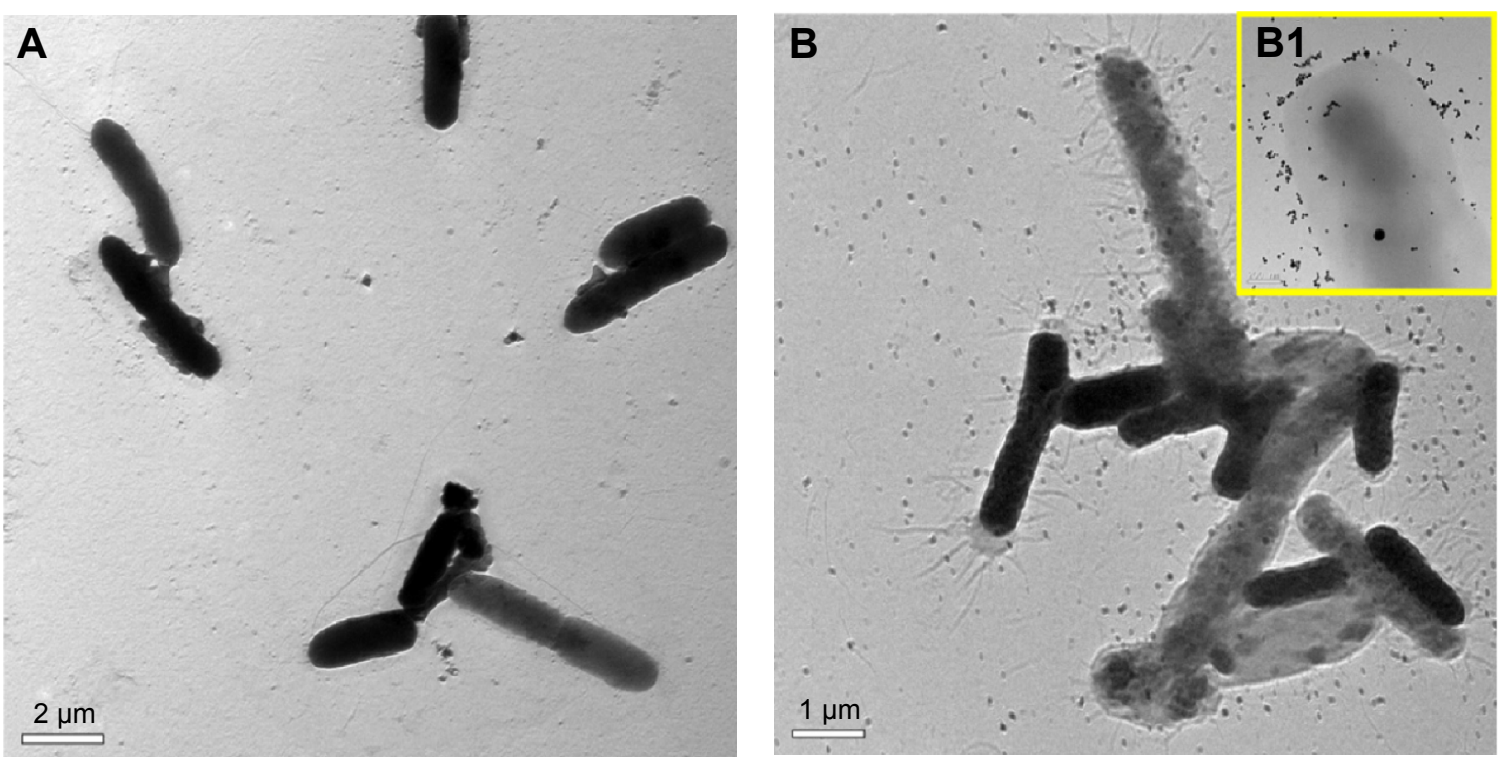

Figure 8 Transmission electron micrographs of Escherichia coli before and after treatment with GlcN-AuNPs.

Notes: (A) Bacteria before treatment with GlcN-AuNPs showing clear and well structured morphology. (B) Bacteria after treatment with GlcN-AuNPs showing damaged cell membranes and ruptured structures. (BI) Inset image shows nanoparticles attached and surrounding E. coli. Abbreviations: AuNPs, gold nanoparticles; GlcN-AuNPs, glucosamine-functionalized gold nanoparticles.
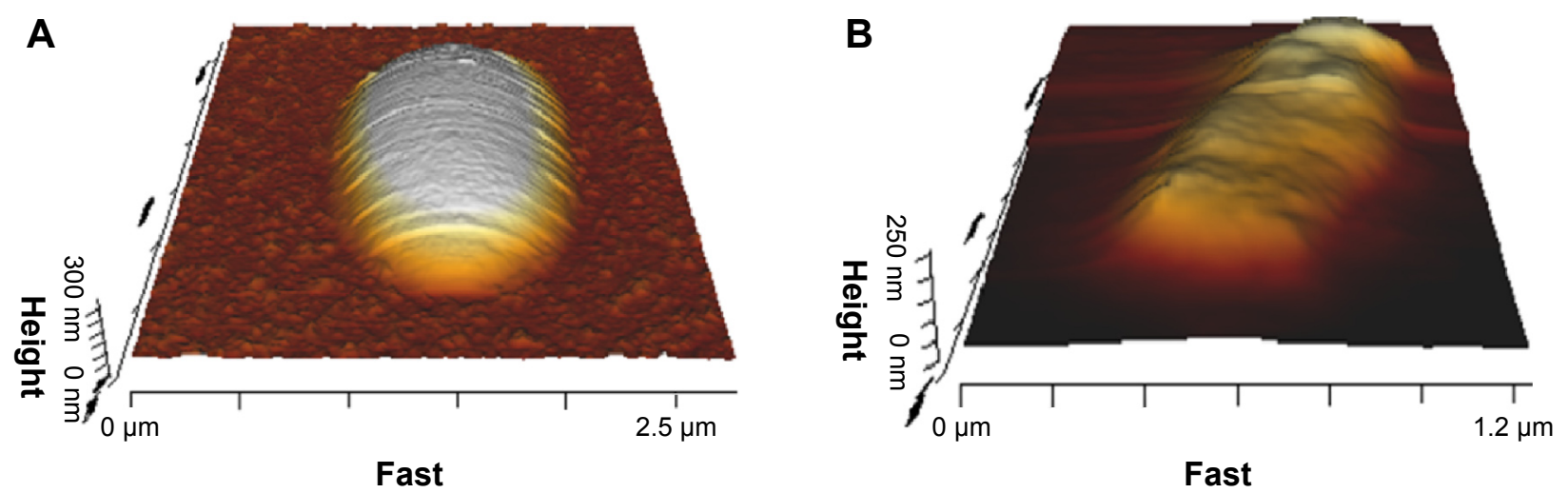

Fast

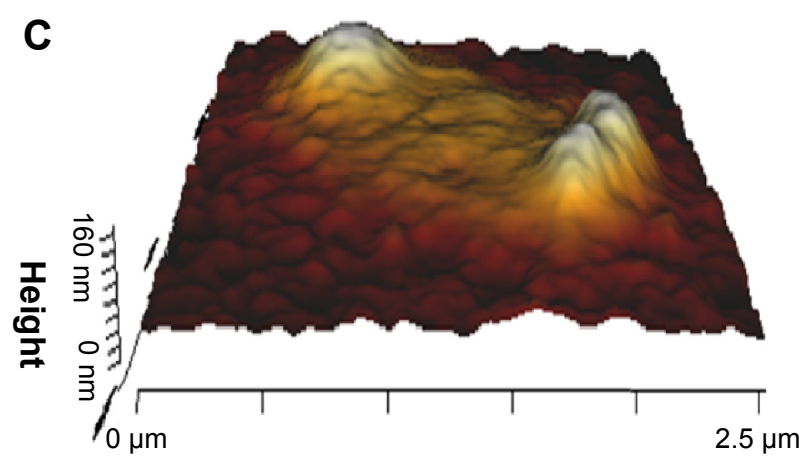

Fast

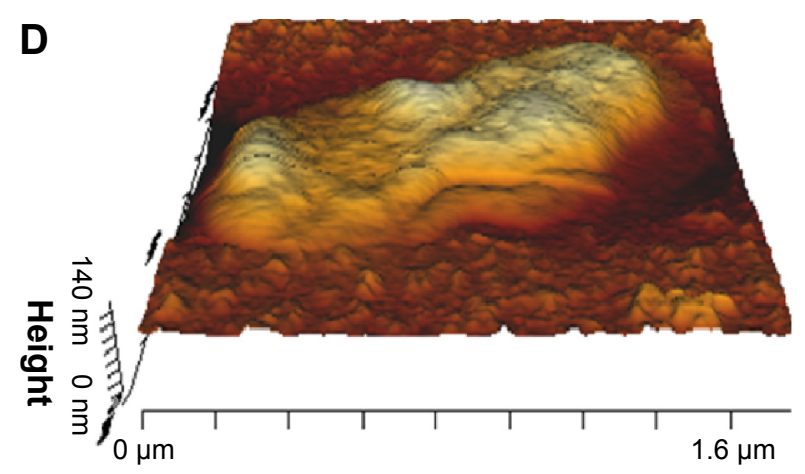

Fast

Figure 9 Atomic force micrographs showing time-dependent morphological changes in Escherichia coli before and after treatment with glucosamine-functionalized gold nanoparticles.

Notes: (A) 0 hour, (B) 6 hours, (C) 12 hours, and (D) 24 hours. At 0 hour, no morphological changes were observed. After 24 hours of treatment, the bacterial morphology was changed, and confirmed by the height (refer to $y$-axis of figures) of the bacteria, which decreased from $300 \mathrm{~nm}$ to $140 \mathrm{~nm}$. 
A

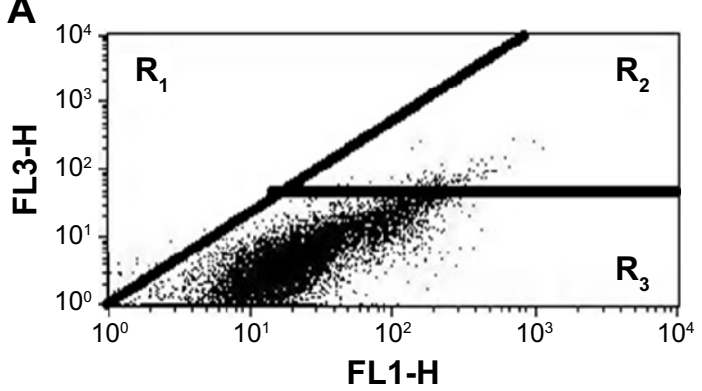

C

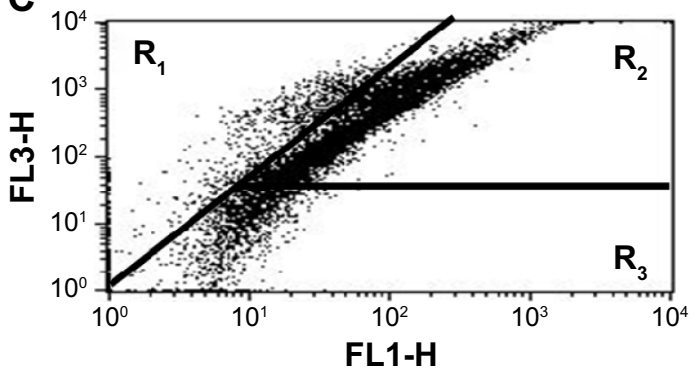

E

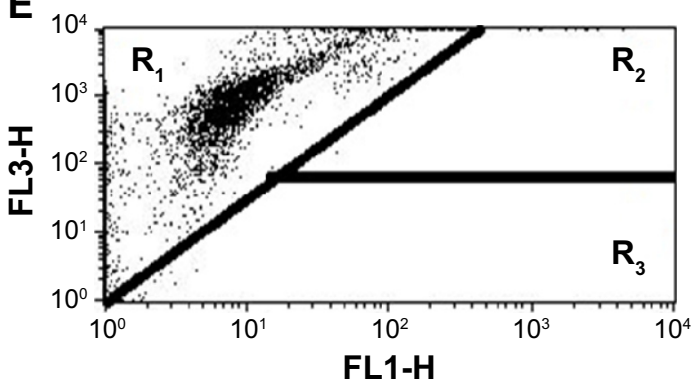

B

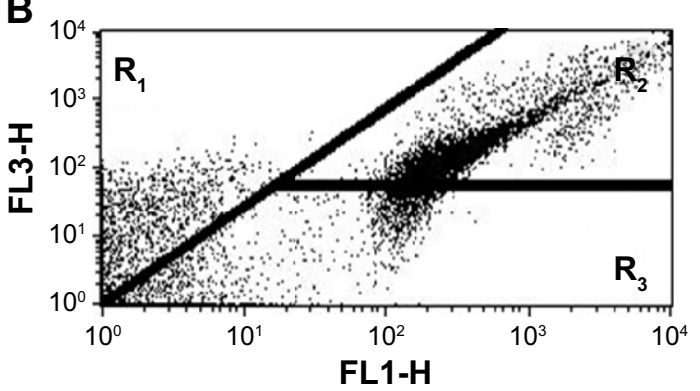

D

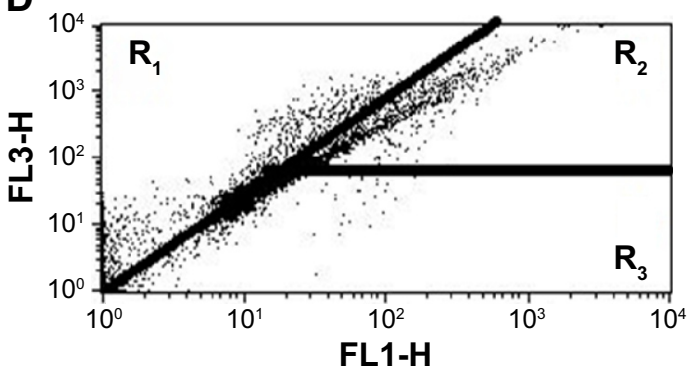

$\mathbf{F}$

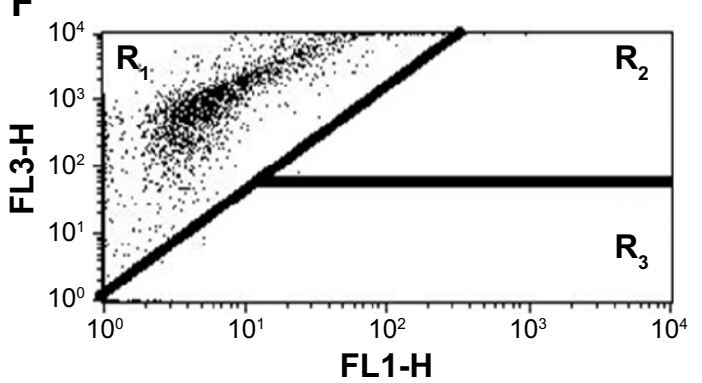

Figure 10 Flow cytometry analysis of Escherichia coli.

Notes: (A) Bacteria treated with medium only as a control, (B) bacteria treated with AuNPs, (C) bacteria treated with GlcN-AuNPs, (D) bacteria treated with ultravioletirradiated GlcN-AuNPs, (E) bacteria treated with laser-irradiated GlcN-AuNPs, and (F) bacteria treated with standard kanamycin.

Abbreviations: AuNPs, gold nanoparticles; GlcN-AuNPs, glucosamine-functionalized gold nanoparticles; R, R-region.

whereas red fluorescing propidium iodide only enters cells with a damaged membrane. Figure 11 shows maximum green intensity in the control, whereas AuNP-treated bacteria shows intense green and red staining. However, for GlcN-AuNPtreated bacteria, the intensity of red fluorescence was increased compared with the control and AuNP-treated bacteria, and the intensity of red fluorescence increased further in bacteria treated with ultraviolet light and laser. The maximum intensity was observed in laser-exposed GlcN-AuNP-treated bacteria. The standard sample of kanamycin-treated bacteria also showed maximum red fluorescence intensity, indicating that bacteria were being killed. These results are consistent with those for the antibacterial study and flow cytometry.

\section{Conclusion}

In conclusion, we successfully synthesized stable GlcN-AuNPs, and characterized them analytically, morphologically, and biologically. Morphological changes in nanoparticle-treated $E$. coli were also studied. The visible absorbance of AuNPs and that in response to varying concentrations of glucosamine in GlcN-AuNPs was confirmed by ultraviolet-visible spectroscopy. The average size of the nanoparticles in the synthesized formulations was in the range of 100.51-78.39 nm, indicating that the particle size decreased in response to increasing concentrations of glucosamine. Morphological characterization of the prepared AuNPs identified a spherical shape in all formulations. Raman spectroscopy identified $\delta$ (CC) and C-C skeletal vibrations and $\mathrm{N}-\mathrm{C}=\mathrm{O}$ group bending. Using the microdilution method, GlcN-AuNPs were found to have pronounced in vitro antibacterial activity. Morphological changes in E. coli microbes after treatment with the nanoparticles were characterized using AFM and TEM. The effect on the bacterial cell cycle was investigated by fluorescence-activated cell sorting analysis and the laser treated functionalized AuNPs found to be maximum cell cycle arrest, was observed by 

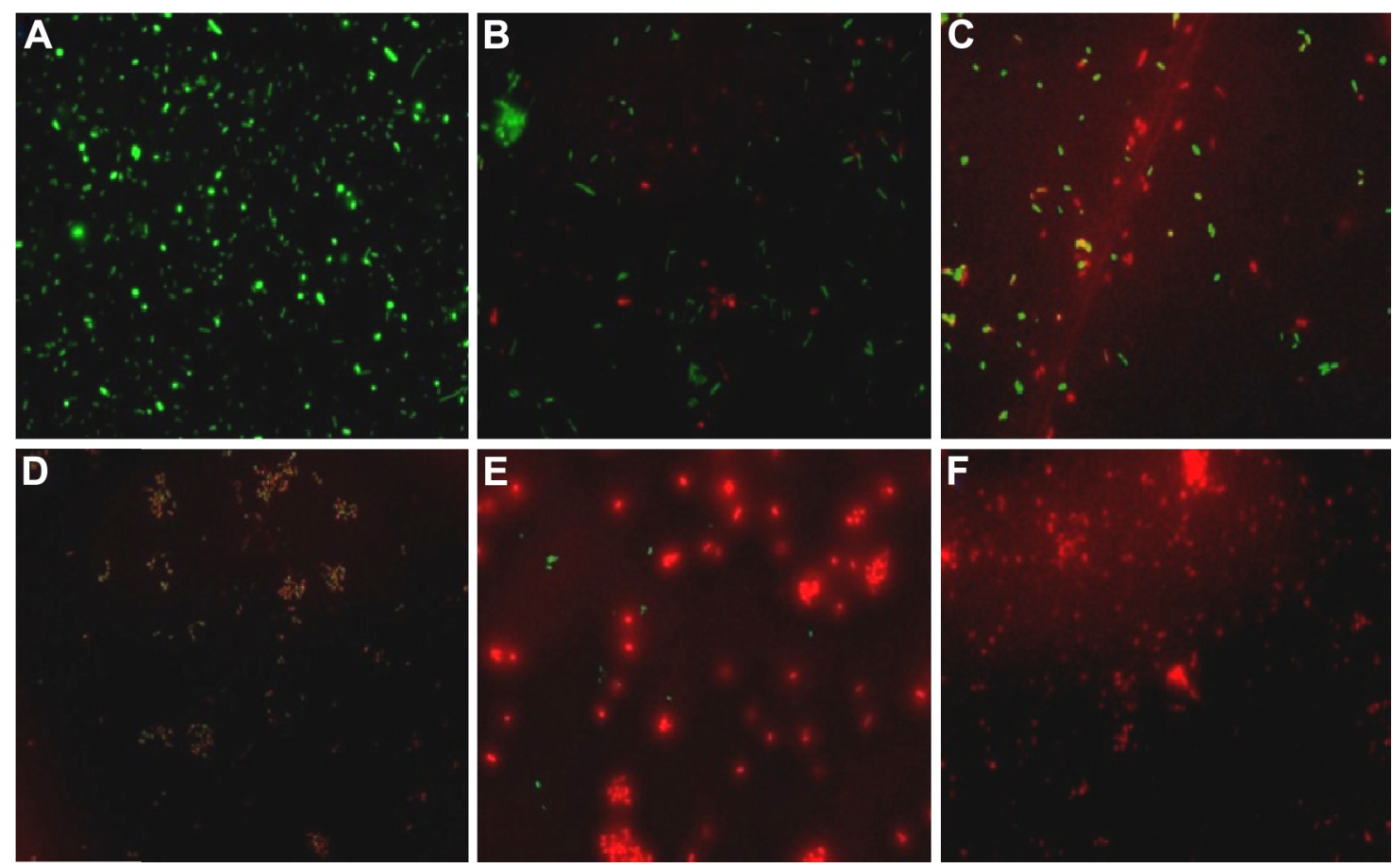

Figure II Fluorescence micrographs of Escherichia coli.

Notes: (A) Bacteria treated with medium only as a control, (B) bacteria treated with AuNPs, (C) bacteria treated with GlcN-AuNPs, (D) bacteria treated with ultravioletirradiated GlcN-AuNPs, (E) bacteria treated with laser-irradiated GlcN-AuNPs, and (F) bacteria treated with standard kanamycin. Green indicates live bacteria and red indicates dead bacteria.

Abbreviations: AuNPs, gold nanoparticles; GlcN-AuNPs, glucosamine-functionalized gold nanoparticles.

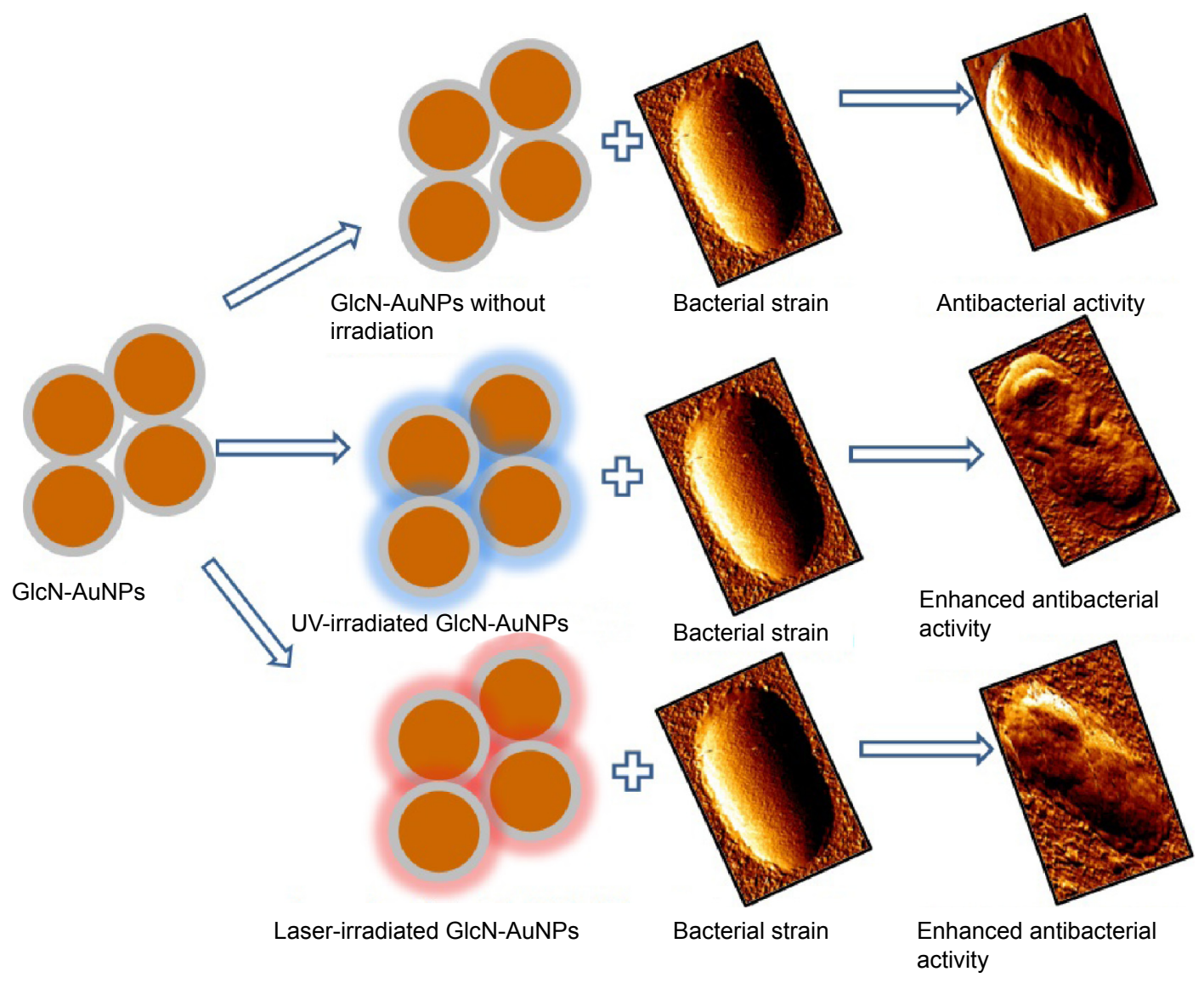

Figure 12 Schematic diagram for antibacterial activity of prepared nanoparticles.

Abbreviations: AuNPs, gold nanoparticles; GlcN-AuNPs, glucosamine-functionalized gold nanoparticles; UV, ultraviolet light. 
fluorescence-activated cell sorting analysis. Fluorescence was used to identify live/dead E. coli with and without treatment with nanoparticles. Finally, biocompatible synthesis of functionalized AuNP strategy, size control properties could lead to many applications, including antimicrobial agents for use in the water treatment, textile, and pharmaceutical industries.

\section{Acknowledgments}

This research was supported by the GRRC Program of Gyeonggi Province (2014-B03) and in part by the Nano-Material Technology Development Program through the National Research Foundation of Korea (2011-0030233).

\section{Disclosure}

The authors report no competing interests in this work.

\section{References}

1. De Jong WH, Borm PJ. Drug delivery and nanoparticles: applications and hazards. Int J Nanomedicine. 2008;3(2):133-149.

2. Hajipour MJ, Fromm KM, Akbar Ashkarran A, et al. Antibacterial properties of nanoparticles. Trends Biotechnol. 2012;30(10):499-511.

3. Daima HK, Selvakannan P, Shukla R, Bhargava SK, Bansal V. Finetuning the antimicrobial profile of biocompatible gold nanoparticles by sequential surface functionalization using polyoxometalates and lysine. PLoS One. 2013;8(10):e79676.

4. Gajjar P, Pettee B, Britt DW, Huang W, Johnson WP, Anderson AJ. Antimicrobial activities of commercial nanoparticles against an environmental soil microbe, Pseudomonas putida KT2440. J Biol Eng. 2009;3(9): $1-13$.

5. Ravishankar Rai V, Jamuna Bai A. Nanoparticles and their potential application as antimicrobials. In: Méndez-Vilas A, editor. Science Against Microbial Pathogens: Communicating Current Research and Technological Advances. Badajoz, Spain: Formatex Research Center; 2011.

6. Silver S, Phung LT, Silver G. Silver as biocides in burn and wound dressings and bacterial resistance to silver compounds. J Ind Microbiol Biotechnol. 2006;33(7):627-634.

7. Chithrani BD, Ghazani AA, Chan WC. Determining the size and shape dependence of gold nanoparticle uptake into mammalian cells. Nano Lett. 2006;6(4):662-668.

8. Jumaa T, Chasib M, Hamid MK, Al-Haddad R. Effect of the electric field on the antibacterial activity of Au nanoparticles on some Gram-positive and Gram-negative bacteria. Nanosci Nanotechnol Res. 2014;2(1):1-7.

9. Niemirowicz K, Swiecicka I, Wilczewska AZ, et al. Gold-functionalized magnetic nanoparticles restrict growth of Pseudomonas aeruginosa. Int J Nanomedicine. 2014;9:2217-2224.

10. Pissuwan D, Cortie CH, Valenzuela SM, Cortie MB. Functionalised gold nanoparticles for controlling pathogenic bacteria. Trends Biotechnol. 2010;28(4):207-213.
11. Luckarift HR, Balasubramanian S, Paliwal S, Johnson GR, Simonian AL. Enzyme-encapsulated silica monolayers for rapid functionalization of a gold surface. Colloids Surf B Biointerfaces. 2007;58(1):28-33.

12. Vo KD, Kowandy C, Dupont L, Coqueret X, Hien NQ. Radiation synthesis of chitosan stabilized gold nanoparticles comparison between e-beam and $\gamma$ irradiation. Radiat Phys Chem. 2014;94:84-87.

13. Fox BA, Stephens MM. Glucosamine hydrochloride for the treatment of osteoarthritis symptoms. Clin Interv Aging. 2007;2(4):599-604.

14. Huang H, Yang X. Synthesis of chitosan-stabilized gold nanoparticles in the absence/presence of tripolyphosphate. Biomacromolecules. 2004; 5(6):2340-2346.

15. Rotilie CA, Fass RJ, Prior RB, Perkins RL. Microdilution technique for antimicrobial susceptibility testing of anaerobic bacteria. Antimicrob Agents Chemother. 1975;7(3):311-315.

16. Alfons K, Engstrom S. Drug compatibility with the sponge phases formed in monoolein, water, and propylene glycol or poly (ethylene glycol). J Pharm Sci. 1998;87(12):1527-1530.

17. Jin Y, Li Z, Hu L, Shi X, Guan W, Du Y. Synthesis of chitosan-stabilized gold nanoparticles by atmospheric plasma. Carbohydr Polym. 2013; 91(1):152-156.

18. Kuo C-H, Chiang T-F, Chen L-J, Huang MH. Synthesis of highly faceted pentagonal-and hexagonal-shaped gold nanoparticles with controlled sizes by sodium dodecyl sulfate. Langmuir. 2004;20(18):7820-7824.

19. Bhumkar DR, Joshi HM, Sastry M, Pokharkar VB. Chitosan reduced gold nanoparticles as novel carriers for transmucosal delivery of insulin. Pharm Res. 2007;24(8):1415-1426.

20. Israelsen ND, Hanson C, Vargis E. Nanoparticle properties and synthesis effects on surface-enhanced Raman scattering enhancement factor: an introduction. Scientific World Journal. 2015;2015:124582.

21. Veerapandian M, Sadhasivam S, Choi J, Yun K. Glucosamine functionalized copper nanoparticles: preparation, characterization and enhancement of anti-bacterial activity by ultraviolet irradiation. Chem Eng J. 2012;209:558-567.

22. Lambert JB, Shurvell HF, Cooks RG. Introduction to Organic Spectroscopy. 1st ed. New York, NY, USA: Macmillan; 1987.

23. Kumar MN, Muzzarelli RA, Muzzarelli C, Sashiwa H, Domb AJ. Chitosan chemistry and pharmaceutical perspectives. Chem Rev. 2004; 104(12):6017-6084.

24. Veerapandian M, Lim SK, Nam HM, Kuppannan G, Yun KS. Glucosamine-functionalized silver glyconanoparticles: characterization and antibacterial activity. Anal Bioanal Chem. 2010;398(2):867-876.

25. Zhang W, Li Y, Niu J, Chen Y. Photogeneration of reactive oxygen species on uncoated silver, gold, nickel, and silicon nanoparticles and their antibacterial effects. Langmuir. 2013;29(15):4647-4651.

26. Manke A, Wang L, Rojanasakul Y. Mechanisms of nanoparticle-induced oxidative stress and toxicity. Bio Med Res Int. 2013;2013:15.

27. Hu M, Chen J, Li Z-Y, et al. Gold nanostructures: engineering their plasmonic properties for biomedical applications. Chem Soc Rev. 2006; 35(11):1084-1094.

28. Hu B, Zhang L-P, Chen X-W, Wang J-H. Gold nanorod-covered kanamycin-loaded hollow SiO2 (HSKAu rod) nanocapsules for drug delivery and photothermal therapy on bacteria. Nanoscale. 2013;5(1): 246-252.

29. Ramasamy M, Lee SS, Yi DK, Kim K. Magnetic, optical gold nanorods for recyclable photothermal ablation of bacteria. J Mater Chem B. 2014; 2(8):981-988.

\section{Publish your work in this journal}

The International Journal of Nanomedicine is an international, peerreviewed journal focusing on the application of nanotechnology in diagnostics, therapeutics, and drug delivery systems throughout the biomedical field. This journal is indexed on PubMed Central, MedLine, CAS, SciSearch $\AA$, Current Contents ${ }^{\circledR} /$ Clinical Medicine,

\section{Dovepress}

Journal Citation Reports/Science Edition, EMBase, Scopus and the Elsevier Bibliographic databases. The manuscript management system is completely online and includes a very quick and fair peer-review system, which is all easy to use. Visit http://www.dovepress.com/ testimonials.php to read real quotes from published authors. 